\title{
A Study of Factor Analysis Affecting Major Crimes by Using R Program
}

\author{
Hyeon-Kyung Lee ${ }^{1}$ and Jong-Bae Kim ${ }^{2 *}$ \\ ${ }^{1}$ Graduate School of Software, Soongsil University, Seoul 156-743, Korea \\ ${ }^{2 *}$ Graduate School of Software, Soongsil University, Seoul 156-743, Korea \\ ${ }^{1}$ ketia89@naver.com, ${ }^{2 *} k j b 123 @ s s u . a c . k r$
}

\begin{abstract}
CCTV(Closed Circuit Television) is a decisive means in coping with crime investigations and arresting criminals. CCTV not only provides efficient directions for crime investigations but is highly useful to do a security check, personal inquiries, and reconstruction of accidents. However, it is not always safe out of felony or major crimes to install CCTVs in vulnerable crime areas. Furthermore, it is even vague to analyze the causes of major crimes and examination of crime environments. In addition, considering diverse local boroughs in Seoul, it is not simple to assume this or that crime cause. Therefore, this paper investigated the analysis of correlation with major crimes and multiple linear regression analysis through the statistic program $R$ by collecting the number of street lamps, CCTVs, seniors, populations, incoming populations, outcoming populations, and housing owners in each local borough from 2010 to 2014. For this purpose correlation analyzed number of street lamps, incoming population, CCTVs, and seniors respectively. Before analyzing multiple linear regression analysis, we excluded existing inappropriate variables which greatly affect by selecting the greatest subset through the seven independent variables. As a result of the greatest subset, we could find that the independent variables affecting major crimes were the number of street lamp, incoming population and housing owners. According to the result of analyzing subordinate variables and independent variables, each of p-value, $R 2$, was suitable and for the independent variables in connection with reliability scope, all of them were included within the boundary of reliability. In this study using a factor analysis presented are expecting an effect capable of suppressing the violent crimes.
\end{abstract}

Keywords: Factor Analysis, Major Crime, R Program, Correlation Analysis, Multiple Linear Regression Analysis

\section{Introduction}

Although various IT technologies contributed to our current abundant lives, major crimes also increase in proportion to them. Since after 2000s, five major crimes (murder, robbery, rape and sexual molestation, theft, violence) have continuously on the rise. The tendency of theft and violence accounts for more than 90\%; whereas, sexual violence (rape and sexually disgraceful conduct) is steeply on the rise too. According to the average of five major crimes in Seoul for the last three years from 2010 to 2012, it amounts to 131,704 cases. The average case per 100 thousand reaches 1,285 cases [1].

Indeed, there have been made diverse study models at the initial stage of studying crimes. Interestingly, it has been actively studying on what causes crimes with the passage of time.

Received (November 5, 2017), Review Result (January 15, 2018), Accepted (January 24, 2018)

* Corresponding Author 
Table 1. 5 Major Crime Situation of Seoul

\begin{tabular}{|l|l|l|l|l|}
\hline Division & 2010 & 2011 & 2012 & A verage \\
\hline $\begin{array}{l}\text { Case per } 5 \text { major } \\
\text { crime }\end{array}$ & $\mathbf{1 2 4 , 4 4 7}$ & $\mathbf{1 3 2 , 9 3 9}$ & $\mathbf{1 3 7 , 7 2 5}$ & $\mathbf{1 3 1 , 7 0 4}$ \\
\hline Case per 100,000 & $\mathbf{1 , 2 0 7}$ & $\mathbf{1 , 2 9 7}$ & $\mathbf{1 , 3 5 1}$ & $\mathbf{1 , 2 8 5}$ \\
\hline
\end{tabular}

Table 2. Frequency of Occurrence of 5 Major Crime Areas

\begin{tabular}{|l|l|l|l|l|}
\hline Division & Type & Rank of Crime & \\
\hline \multirow{3}{*}{$\begin{array}{c}\text { Case per } \\
\text { 5 major } \\
\text { crime }\end{array}$} & Murder & Yeongdeungpogu & Gangnamgu & Dongdaemungu \\
\cline { 2 - 5 } & Robbery & Gangnamgu & Dongdaemungu & Yeongdeungpogu \\
\cline { 2 - 5 } & Rape & Gangnamgu & Gwanakgu & Seochogu \\
\cline { 2 - 5 } & Violence & Gangnamgu & Yeongdeungpogu & Jungrangu \\
\cline { 2 - 5 } & Theft & Gangnamgu & Songpagu & Yeongdeungpogu \\
\hline \multirow{4}{*}{$\begin{array}{c}\text { Case per } \\
\text { density }\end{array}$} & Murder & Yeongdeungpogu & Geumcheongu & Jongrogu \\
\cline { 2 - 5 } & Robbery & Dongdaemungu & Gwangjingu & Dongdaemungu \\
\cline { 2 - 5 } & Rape & Gwanakgu & Gwangjingu & Gwanakgu \\
\cline { 2 - 5 } & Violence & junggu & Jungrangu & junggu \\
\cline { 2 - 5 } & Theft & junggu & Gwangjingu & Gwanakgu \\
\hline
\end{tabular}

There have been preceding studies on the close relationships between major crimes and the correlations with violence and rape or murder and intensity as well [2]. Considering the characteristics of crime vulnerable areas, crimes happens easily around one person family, low income household, districts of many flowing populations as well as narrow alleys. Many studies have been made in terms of spatial perspectives and great efforts are still being made to prevent crimes by improving surrounding environment [3]. For this purpose, it is critical to analyze the causes and factors of crimes in connection with the space study [4].

Therefore, this paper investigated the analysis of correlation with major crimes and multiple linear regression analysis through statistic program $\mathrm{R}$ by collecting the number of street lamps, CCTVs, seniors, populations, incoming populations, outcoming populations, housing owners in each local boroughs from 2010 to 2014. This study will certainly be helpful in coping with major crimes in future by referring to the suggestive factor analysis.

\section{Releated Study}

Diverse studies for preventing crimes have been started from criminology, sociology, and criminals. According to the crime economy theory, all human beings have a free will and choose rational choices by comparing convenience and expenses.

When it comes to the crime economy theory, crimes are closely related to the economic factors. Becker (1968) insisted that the extension of labor market is related to the crime rate. Levitt(2004) concluded that economic factors are less related to the crimes of rape, violence and murder, but considerably related to the crimes of theft, robbery, financial felony, and vehicle crimes [5].

Crimes, from the perspective of crime economy, are formed in the relation of expense convenience and criminal act as a result of rational expectation. That's why it is important to analyze the factors of crimes. Furthermore, crimes occur as their types become subdivided and complicated with the flow of time. More specifically, complicate circumstances like violence or rape are likely to heighten the possibility of crimes, which requires doing practical investigation of the correlation with crimes.

Establishing additional preventive CCTV and the increasing number of police as well as enforcing round of inspection are not only an effective means to prevent crimes but 
also to eliminate a sense of uneasiness. Nevertheless, due to the lack of financial budget, practical preventing crimes are not fulfilled. In order to solve these practical issues, CPTED (Crime Prevention through Environmental Design) is considered a potential way to fulfil such a measure [13].

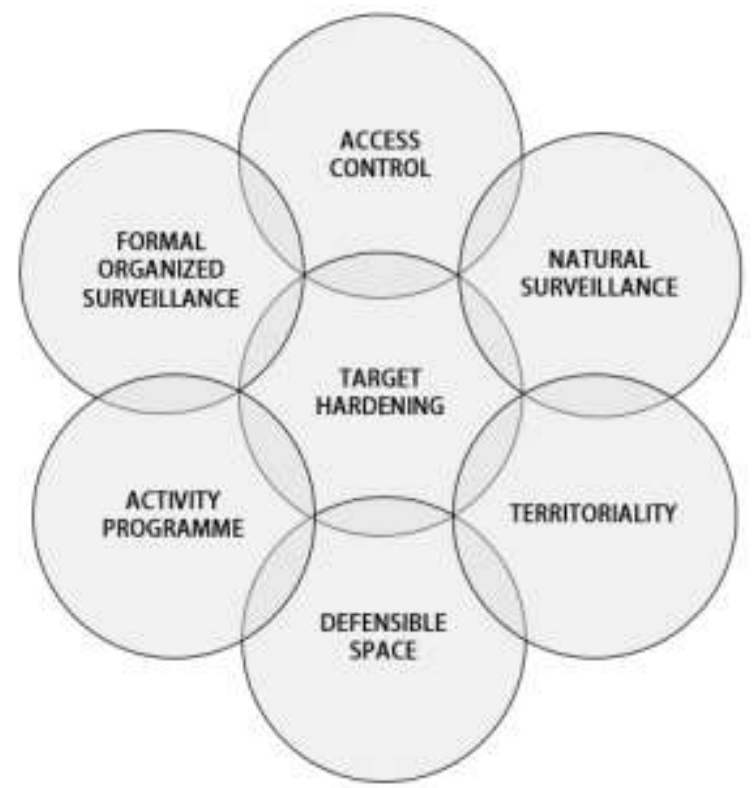

Figure 1. CPTED Diagram

CCTV is divided following its purpose and use such as for protecting children, preventing crimes, for cracking down traffic, for inspecting suspected arrangement traffic, for calamities and damages, and for managing facilities. However, CCTV required in the relationship with CPTED is used for preventing crimes and inspecting arrangement traffic.

For this purpose, Gangdong-gu district upgrade the function of CCTV by applying CPTED to preventing CCTV one step further. When it comes to the selecting places of $\mathrm{CCTV}$, the priority is to analyze the potential place of crimes as well as vulnerable subjects through the technique of big data by cooperating with city police in times of accidents and by applying two million HD ultraviolet cameras [14].

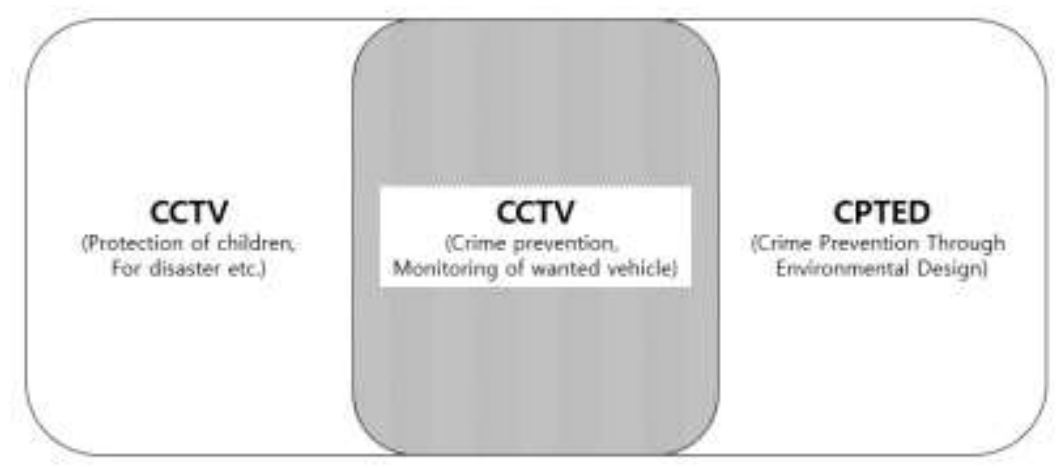

Figure 2. Interrelationships with CCTV and CPTED

As for Yeomri-dong, Mapo-gu district since after April 2012, it has been activating the campaign of "Sogeum-gil Street" so as to keep eyes on the street by linking vulnerable alleys for residents. Furthermore, it has painted the door in yellow and established bright light, camera, and emergency bells by appointing seven "Sogeum Safety Houses" among 
those residents who have never involved in crimes and lived there for a long time. For the Sogeum-gil street, it has positively affected to those residents by playing CCTV roles of eliminating a sense of unease through the diverse elements of CPTED.

Park Chul-Hyun, Choi Soo Hyeong(2009)examined how CCTV initially established in Gangnam areas and how it prevented crimes in October 2002 for the last six months and three months respectively. As a result, since after reporting the initial establishment of CCTV in Gangnam-gu district, numbers of burglar and theft has been decreased, whereas those surface crimes such as rapes, murders, and violence disappeared. Plus, with the report of establishing CCTV in Gangnam-gu area, the number of burglar and theft was decreased in those neighborhoods districts such as Seocho-gu, Songpa-gu and others. However, these effects were more evident in case of analyzing them for six months rather than those for three months, which proves that short-term measures are more effective [6].

Min-Hyouk Yim, Jun Hyun Hong(2008) investigated how 24 patrol rounds served as preventive CCTVs in 2008 by limiting the boundary of preventive CCTV by the end of December 2005. As a result, it proved that the establishment of preventive CCTV was not effective to remove those five major crimes per 10,000 people. Therefore, considering the limitation of establishing preventive CCTV, they claimed that it is necessary to work with others [7].

Kang Seok-Jin, Park Ji-Eun, Lee Kyung-Hoon(2009) analyzed the Q and A of those residential subjects for the analysis of effective CCTV to prevent crimes by comparing the current results of research. Thus, they provided the information how numbers of established CCTV in different locations affect to the spatial crimes in road, alley, and theft based on the damages of crime and rates of experiences. As a result, they found that the establishment of CCTV can reduce a feeling of uneasiness for residents [8].

Shin, Woo-Hwa, Shin, Woo-Jin(2012) studied the analysis of correlation with crimes focused on incomplete reconstruction regions due to the prolonged business recession as a part of city readjustment business by dividing them into neighborhoods environment and housing environment [9]. When it comes to physical environment, there were street lamps. Hyo-Chang Lee, Jae-Hwa Lee, Dae-Jin Kim, Mi-Kyoung Ha(2011) suggested that street lamps are needed to promote safe environment from crimes and it needs to maintain luminous intensity continuously so that one can discern people [13].

Likewise, studies on the correlation with city population and crimes are mainly concentrated on a population scale and intensity, movement of population and major crimes. Cho Jongyeop, Baek Yeonsang, Kim Suyeon(2013) examined the correlation with the movement of population rate and major crimes (correlation coefficient: 0.38 ) and found that strong social connections are closely related to the increasing crime rate. Furthermore, according to them, major crimes happen in the affluent districts rather than the population scale [10].

Oh Mijin(2011) examined that crime rates are higher in the downtown than suburban areas of a metropolis in which flowing population is high. She further studied how the movement of population can more affect crimes rather than the intensity of population. As a usual, crimes happen more frequently especially in the area of many flowing population districts such as entertainment center or accommodation areas. Lee Seongwoo and Cho Joonggu(2006) studied how entertainment centers, restaurants, and accommodation areas are closely related to major crimes.

Lee, Jong-Hoon, Yoo, Seung-Kyu, Kim, Ju-Hyung, Kim, Jae-Jun(2013) further studied how housing values and local characteristics are closely related to the crimes as chief factors of crimes. Physical environment such as CCTVs and street lamps can affect housing values and cause insecurity of residents including the values of real estate [11].

In closing, physical environment such as local characteristics and population are closely related to crimes, not just economic factors and environmental factors like CCTVs. 


\section{Data Analysis}

\subsection{Data Collection and Settlement}

We downloaded major crime data and CCTV chart data from those of Seoul city. Besides, calculation data come from the government 3.0 public data site (www.data.go.kr) and the data of square, population, senior, incoming population and outcoming population come from Seoul city statistics (stat.seoul.go.kr). When it comes to street lamps, we referred to Seoul open data site (data.seoul.go.kr).

When it comes to housing extension rate, we referred to national statistic site (kosis.kr). We used analyzed data from 2010 to 2014 for five years. However, as long as incoming population and outcoming population are concerned, we downloaded them just in 2010, whose data are collected every five years. In addition, we incorporated downloaded data to analyze them into one and made every objective data as a standard form by setting every data value in every borough per $1 \mathrm{~km}^{2}$.

Data column name is made up of as follows: borough, Murder, Robber, Rape, Theft, Violence, Number of major crimes, Lamp, CCTVs, Seniors, Population, Incoming_Population, Outcoming_Population, Procession_of_House and Year respectively.

Data column name is made up of as follows: borough, Murder, Robber, Rape, Theft, Violence, Number of major crimes, Lamp, CCTVs, Seniors, Population, Incoming_Population, Outcoming_Population, Procession_of_House and Year respectively.

\subsection{Seoul City CCTV Data}

Seoul City CCTV data come from the government 3.0 sites in Kangnam, Kangdong, Kangseo, Gwanak, Gwangjin, Geumcheon, Songpa, Yeongdeungpo, Eunpyeong, Jongro borough. The total data are 7,899 cases, in which 5,486 cases were visualized the chart values except for irrelevant CCTVs. In addition, when it comes to other data, there were difficulties in visualizing data provided by Seoul city.

\begin{tabular}{|c|c|c|c|c|c|c|c|c|c|c|c|c|c|c|c|}
\hline Tenters & & & & & & & & & & & & & & \multicolumn{2}{|l|}{$=$} \\
\hline S 0 & 7 Fitar & & & & & & & & & & & & Q & & \\
\hline Counry & Nerder & Botber: & Pape: & Toeht: & Vídeve: & Clate: & Lasp: & $\mathrm{CCT}$ & Seriox & Poolation: & bxxeing hpotarion = & Ottcosing fopetation: & Arocession of Hase & $y_{a z}$ & \\
\hline $18 \div$ & 11 & 31 & 178 & 1962 & 2084 & 127 & 22 & 15 & 4334 & 146: & 14776 & $3 \pi 2$ & sen: & 2010 & A \\
\hline 2 ํㅗㅇา & 5 & 15 & $\%$ & III & 1285 & 54 & 233 & $\varepsilon$ & 6221 & ment & 2374 & 5539 & 6334 & 4. 2010 & \\
\hline 3 ํำ? & 3 & 11 & 56 & 751 & 980 & $\pi$ & 178 & 5 & 6135 & 14831 & 1659 & 3959 & 1569 & 3. 2010 & \\
\hline $4: 367$ & 18 & 24 & $4 \quad 148$ & 1739 & ase & कs & 157 & 4 & + 4751 & 14022 & 213 & 3524 & $4 \mathrm{sI}$ & 1. 210 & \\
\hline 5 패우 & 2 & II & 108 & $\mathrm{~m}$ & $15 s$ & 32 & 188 & 2 & 6633 & 18572 & 243 & 5332 & 6005 & 5. 2010 & \\
\hline 6 ำㄴำ & 9 & 4 & 131 & $12 \mathrm{~m}$ & 1936 & 194 & $4 \quad 233$ & $x$ & 7326 & 22735 & 528 & EA64 & $\mathrm{ss} 2$ & 2. 2010 & \\
\hline 3. 고구 & 9 & II & 8 & 1159 & 1285 & 129 & 313 & 11 & 7675 & 22521 & 120 & รมำ & 6049 & 22010 & \\
\hline 8 근년 & 13 & 57 & 7. 157 &  & 2738 & $36 \pi$ & 358 & 16 & 6. 732 & xต1 & $7 x$ & 4586 & 633 & 1. 310 & \\
\hline 9487 & 34 & 74 & $4 \quad 24$ & 2648 & 302 & 106 & 242 & 6 & 6335 & 17315 & 2918 & 4507 & 5663 & 3. 2010 & \\
\hline 10. 5 퐁? & 11 & 25 & se & 1350 & $17 x$ & 153 & 205 & 3 & 7221 & 179 & 1780 & 5132 & $\$ 644$ & 4. 2010 & \\
\hline 11 돕른ㄱ & 8 & 36 & $2 \pi$ & 758 & 2073 & 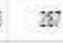 & 583 & 51 & 1) 7610 & 26714 & 5511 & 8501 & 8725 & 52010 & \\
\hline 12 동년? & 11 & 52 & 230 & $25 \% 4$ & 2715 & 32 & 271 & n & 1068 & 28233 & sIT: & 7557 & 8665 & 5. 2010 & \\
\hline 13 미포 & 7 & 12 & 83 & 775 & 119 & s & 253 & 3 & 6855 & 16825 & 6518 & 4598 & 507 & 2010 & \\
\hline 14. 시로국 & 8 & 35 & $5 \quad 120$ & 1522 & 1978 & 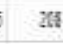 & 280 & 13 & 8758 & $180 \%$ & 7183 & 4390 & 0227 & 7. 2010 & \\
\hline 15. ․ㅐ축 & 19 & $\mathrm{IU}$ & 146 & 300 & 5656 & 213 & 217 & Ts & 3132 & 9662 & $5 m e$ & 2397 & 2065 & $5 \quad 2010$ & . \\
\hline
\end{tabular}

Figure 3. Completed Data 


\subsection{Correlation Analysis}

As seen in [Figure 3], we have analysed the correlations with subordinate variables and independent variables by using $\mathrm{R}$ program regarding entire handling. Moreover, we have established Crime as an independent variable and Lamp, CCTV, Senior, Population, Incoming_Population, Outcoming_Population, Procession_of_House as independent variables. When it comes to all independent variables regarding Crime, it shows as following [Figure 4].


Figure 4. Scattered Chart and Crime Variables

When it comes to high correlation with four variables and scattered chart, it shows as [Figure 5]. More specifically, it demonstrates coefficient as [Table 3].
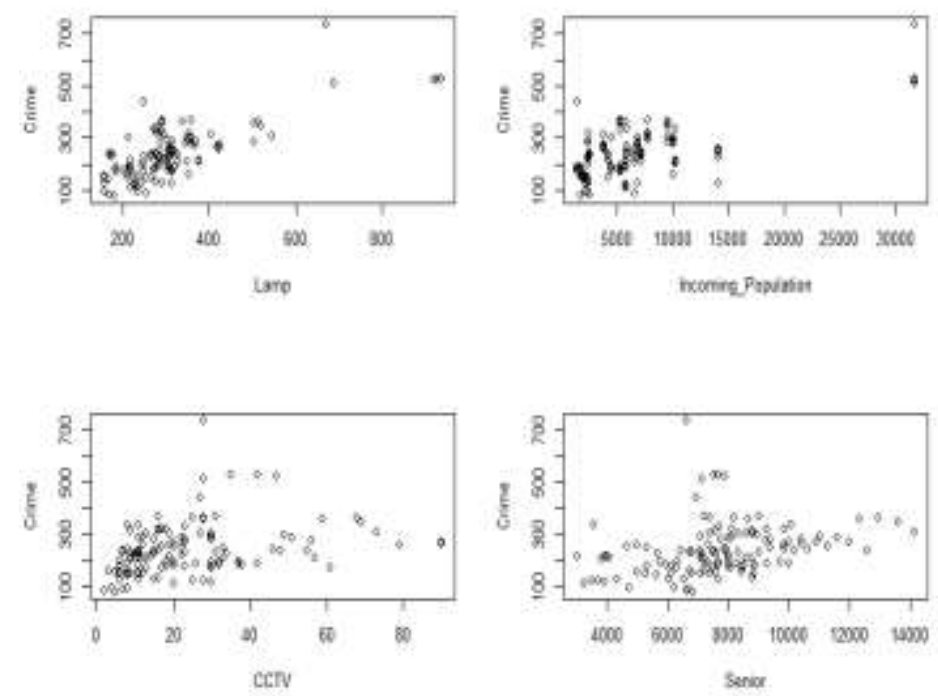
Figure 5. Scattered Chart and High Coefficient Correlation with Crime
Variables 
Lamp and Incoming_Population greatly effect on Crime through each of 0.74 and 0.69 coefficient and [Figure 5] and [Table 3] graph. Plus, it shows that CCTV and senior less affect crime than Lamp, Incoming_Population. Simply put, it is evident that the more frequent crimes happen, the more lamps, incoming populations, and CCTVs as well as seniors. In other words, the variables affecting Crime are just Lamp, Incoming_Population, CCTV, and Senior. However, it does not indicate the cause and effect on variables but concludes potentiality of its correlation.

Table 3. Scattered Chart and High Coefficient correlation with Crime Variables

\begin{tabular}{|l|l|l|l|l|l|}
\hline Division & Crime & Lamp & $\begin{array}{l}\text { Incoming_ } \\
\text { Population }\end{array}$ & CCTV & Senior \\
\hline Crime & 1.00 & - & - & - & - \\
\hline Lamp & 0.75 & 1.00 & - & - & - \\
\hline $\begin{array}{l}\text { Incoming } \\
\text { Population }\end{array}$ & 0.69 & 0.85 & 1.00 & - & - \\
\hline CCTV & 0.33 & 0.48 & 0.21 & 1.00 & - \\
\hline Senior & 0.31 & 0.26 & -0.08 & 0.56 & 1.00 \\
\hline
\end{tabular}

\subsection{Selection of the Greatest Subset}

We preceded the greatest subset method in order to see the way choosing some variables out of analyzed data in [Figure 3] to analyze multiple linear regressions [12]. According to the coefficient 3.3 analysis, the higher coefficient cannot be the appropriate variable regardless of variable residuals. Therefore, we selected the most proper variable after making possible tests as a type of tournament so as to analyze multiple linear regression in this study.

The less AIC value is the more appropriate values become. Thus variable indicated as " +" is not proper variable in each stage. As a result of the greatest subset, it indicated that Lamp, Incoming_Population, Procession_of_House has the greatest impact on Crime.








Figure 6. Greatest Subset Selection

\subsection{Multiple Linear Regression Analysis}

As suggested in [Figure 7], we performed Multiple Linear Regression Analysis by selecting Lamp, Incoming_Population, Procession_of_House as independent variables in terms of 3.4 greatest subset selection affecting Crime. As a result, we proved regression model as seen in [Figure 8]. 


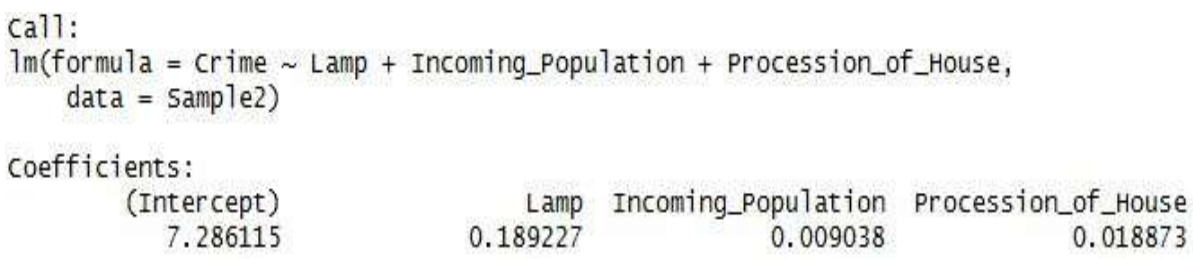

Figure 7. Final Regression Model

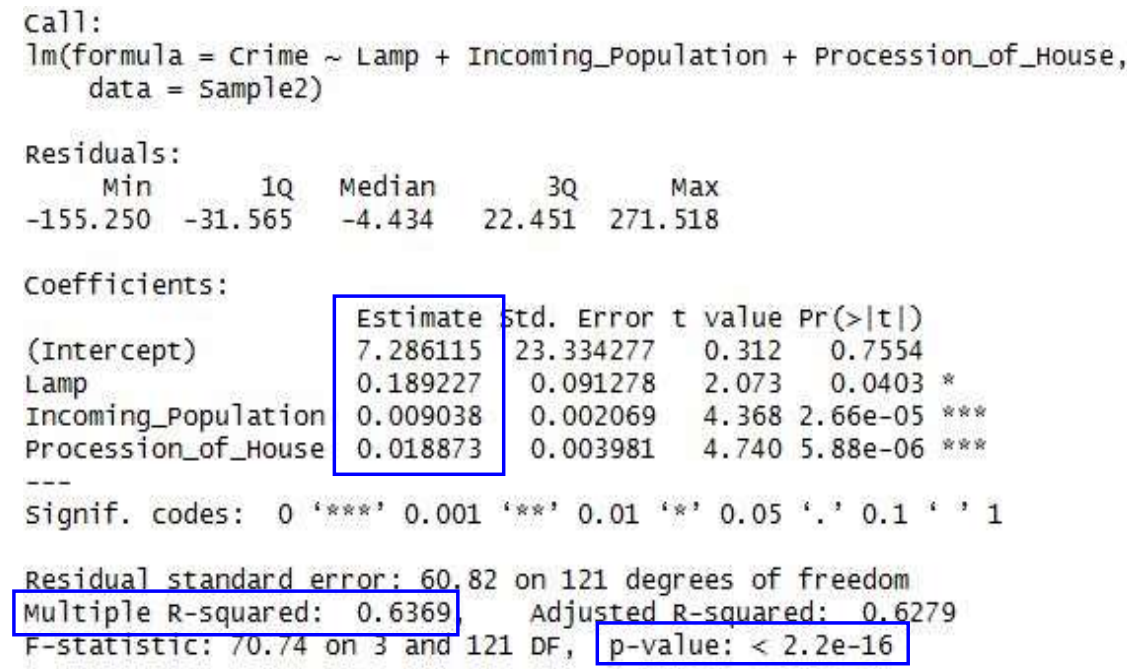

Figure 8. Multiple Linear Regression Analysis Verification

Multiple R-squared represents R2, which means that a value near to 1 decides the appropriateness of regression model. Whereas, $\operatorname{Pr}(>|t|)$ value becomes smaller one less than 0.05 because of the greater possibility of becoming regression coefficient 0 within the scope of $95 \%$ reliability. After examining Estimate so as to make sure each and one of independent variables, I have found that every one of them was included within the boundary of reliability such as 0.189227 Lamp and 0.009038 Incoming_Population, and 0.18873 Procession_of_House.

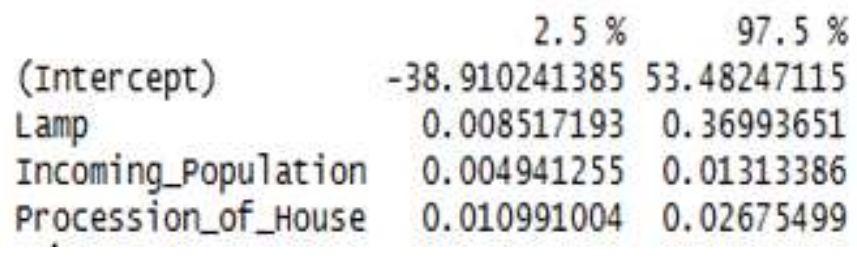

Figure 9. Reliability Scope of Independent Variables

Moreover, when the p-value is less than 0.5 , it can be justified that this regression model is statistically proper [12]. Considering [Figure 8] data, $\mathrm{R} 2$ shows $0.6369, \operatorname{Pr}(>|t|)$ becomes smaller value less than 0.05 , p-value seems to be less than 0.5 .

\section{Conclusion}

In this study, we investigated the analysis of correlation with major crimes and Multiple Linear Regression Analysis through statistic program R by collecting the number of street lamps, CCTVs, seniors, populations, incoming populations, outcoming populations, housing owners in each local boroughs of Seoul from 2010 to 2014. 
This study will certainly be helpful in coping with major crimes in future by referring to the suggestive factor analysis. For this purpose, we performed this analysis by using the correlation function providing $\mathrm{R}$ program and analyzed number of street lamps (0.7464784), incoming population (0.6907082), CCTVs (0.3348914), and seniors (0.3074769) respectively.

Before analyzing multiple linear regression analysis, we excluded existing inappropriate variables which greatly affect by selecting the greatest subset through the seven independent variables. As a result of the greatest subset, we could find that the independent variables affecting major crimes were the number of street lamp, incoming population and housing owners. According to the result of analyzing subordinate variables and independent variables, the regression values became 0.189227, 0.009038, and 0.018873 respectively. When it comes to model verification, each of $\mathrm{p}$-value, $\mathrm{R} 2$, was suitable and for the independent variables in connection with reliability scope, all of them was included within the boundary of reliability.

However, this study has some of limitations and restrictions as well.

First, the correlation analysis and multiple linear regression models are not the result of a cause and effect, but just a straight relationship. Accordingly, one can assume that major crimes are closely related to the number of street lamps. However, one cannot justify them as a cause of effect. More specifically, it needs more additional inner, external, and personal validity including theoretical ground to explicate the cause and effect between subordinate variables and independent variables [12].

Second, the sources of data used in this study were based on the publically accessed data provided by the Korea National Statistical Office and Seoul City. Nevertheless, there were many limitations and restrictions to get access to them.

Unfortunately, we couldn't reflect more possible crime factors. However, it is meaningful for me to have analyzed crime factors through a $\mathrm{R}$ program. In closing, it needs further studies on predicting crimes by inducing affecting factors in case data or coordinate values are extended in each administrative authority.

\section{References}

[1] S.-Y. Shin and J.-K. Jo, "Crime Characteristics of Seoul and City Promotion Plan with Confidence", The Seoul Institute Policy Report, vol. 161, (2014), pp.1-21.

[2] H.-K. Lee, J.-M. Byun, J.P. Jaehyun Choi, Y.-L. Choi and J.-B. Kim, "A Study of Comparative Analysis of Major Crime and CCTV for Crime Prevention through an R program", Advanced Science and Technology Letters (Mechanical Engineering 2016), vol.129, (2016), pp.70-74.

[3] K. Young-Hwan, C. Dong-KuK and M. Jeong-Min, "A study on the analysis of basic crime factors focusing on social and economic factors of 3 cities", Korean Law Association, no. 28, (2007), pp.295311.

[4] H. J. Kim and S. W. Lee, "Determinants of 5 Major Crimes in Seoul Metropolitan Area: Application of Mixed GWR Model”, The Seoul Institute, vol.12, no.4, (2011), pp.137-155.

[5] C. Lee and E. Kim, "An Analysis on Structural Changes in Regional Crime Behaviors before and after Financial Crisis", Journal of the Korean Urban Management Association, vol. 1, no. 25, (2012).

[6] C.-H.Park and S. H. Choi, "Crime Prevention Effects of Publicity of CCTV Installation at Kang-Nam Gu, Seoul: The Effects of First News", Korean criminological review, vol. 20, no. 3, (2009), pp.213238.

[7] M.-H. Yim and J. H. Hong, "Directions of Crime Prevention Policy Through the Analysis of Crime Prevention Effects of CCTV”, KOREAN POLICY SCIENCES REVIEW, vol. 12, no. 4, (2008), pp.77101.

[8] S.-J. Park Kang, J.-E. Lee and K.-Hoon, "An Analysis for Effect of Crime Preventive CCTV in Residential Areas through Public Opinion Survey", JOURNAL OF THE ARCHITECTURAL INSTITUTE OF KOREA Planning \& Design, vol. 25, no. 4, (2009), pp. 235-244.

[9] W.-H. Shin and W.-J. Shin, "A Study of Impact of Urban Population Characteristics on Violent Crimes", Residential Environment(Jorunal Of The Residential Environment Institute Of Korea, vol. 3, no. 10, (2012).

[10] J.-H. Ki, "A Study on the Relationships between Environmental Characteristics in Residential Areas and Crime Occurrences in Daegu Metropolitan City", Journal of The Korean Regional Development Association, vol. 1, no. 27, (2015). 
[11] J.-H. Lee, S.-K. Yoo, J.-H. Kim and J.-J. Kim, "The Effect of Crime-induced Environmental Factors of Residential Area on the Intrinsic Value of Housing", Journal of The Architectural Institute of Korea Planning \& Design, vol.10, no.29, (2013).

[12] C.-S.Park, "Peel R2", SlowThinking Company, (2016).

[13] H.-C.Lee, J.-H. Lee, D.-J. Kim and M.-K. Ha, "A Study on the Direction of the Lighting Plan for CrimeFree in Street of Commercial District", The Seoul Institution, (2011), pp.73-89.

[14] CPTED Guidline, Seoul Korea, (2013).

[15] SeoulCity Article, http://www.seoulcity.co.kr/news/articleView.html?idxno=70464.

\section{Authors}

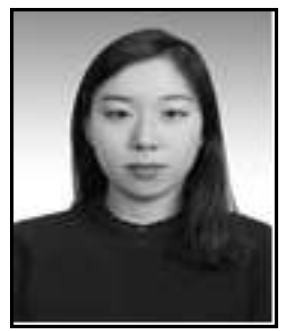

Hyeon-Kyung Lee, she received her bachelor's degree of Computer Information in Baewha Women's University, Seoul (2015). She is studying her master's degree of software engineering in Graduated Soongsil University, Seoul. Her current research interests include Software engineering and Open source software.



Jong-Bae Kim, he received his bachelor's degree of Business Administration in University of Seoul, Seoul(1995) and master's degree(2002), doctor's degree of Computer Science in Soongsil University, Seoul(2006). Now he is a professor in the Graduate School of Software, Soongsil University, Seoul, Korea. His research interests focus on Software Engineering, and Open Source Software. 
International Journal of Advanced Science and Technology

Vol.111 (2018) 